\title{
Counseling and Counseling Services Status in Ethiopia
}

\author{
Getachew Abeshu* and Dinaol Urgessa Gita \\ Department of Psychology, Jimma University, Ethiopia
}

Submission: March 06, 2020; Published: March 20, 2020

*Corresponding author: Getachew Abeshu, Department of Psychology, Jimma University, Ethiopia

\section{Abstract}

The underlying point of reference in the study was obtaining relevant information from modern and professional counselors in the country in view of the societal understanding and interest of using the counseling services in their lifetime. The counseling organizations involved in the study were chosen representing practices of modern counseling structure in the study that has based on certain relevance they could have for the intended lessons. Qualitative study method was conducted employing framework data analysis technique. The tools used to gather information were interview, observation and focus group discussions with key informants of the institutions. The study result identified counseling and counseling service quality is at promising status. Counseling as a tradition among Ethiopian community, specifically the Oromo, become practical to maintain peaceful mental and social serenity even if the extent to which the communities use their own custom needs further consideration.

Keywords: Counseling; Counseling services; Counseling tradition; Psychotherapy; Bio-psychological disorders

\section{Introduction}

The notion, practice and understanding of counseling and counseling service standard are different across continents and countries. In similar manner the state of counseling in Ethiopian context is at promising stage. The disgrace and stigma doting to counseling profession continues and there is a huge wavering with regard to the qualification prerequisites of a counselor and counseling service in various settings [1]. Threats to counseling profession are challenges in the realization of the present-day wide range of prevention and intervention needs of community bodies [2]. Counseling is not in effective progress in that it imposed great harm to culturally diverse groups by invalidating their life experiences, define their cultural values or differences as deviant and pathological, by denying them culturally appropriate care, and magnify the values of a dominant culture upon them [3].

\section{Methods and Material}

Qualitative research approach employing phenomenological research design was used in this study. Counseling organizations involved in the study were chosen purposively since these organizations are considered as they can give enough information about the topic of references. A total of fourteen participants involved in the study. Accordingly, interview guide was used to collect data from the participants purposefully selected one each from two Zonal Culture and Tourism Office, one religious institution and Emanuel Mental Health Specialized Hospital. The Orthodox Church counseling center, religious institution, is central office controlling numerous counseling offices throughout the country. FGD was conducted with six persons in a group where two key informants involved in the interview to secure data. Framework data analysis was employed for the reason that the framework of the study was developed both from a priori issues and emergent issues.

\section{Result and Discussion}

The aim and purpose of counseling in the modern form is poorly understood by the community and the government that in turn stunts development of modern counseling in Ethiopia in addition to the failure professionals demonstrate to incorporate cultural values and community skills in their curriculum of counseling techniques employed in different institutions. With a look upon the counseling department in the Orthodox Church presumed as modern counseling system, counseling service provided were headed by the ordained HIV counselors which are common for most of the institutions employing counseling in the country. 


\section{Psychology and Behavioral Science International Journal}

One of the interviewed counselors stated the following:

We employ modern counseling approach in the pre and posttest HIV counseling sessions. We follow principles of counseling as trained by Family Health International. The major principles are use of GATHER [greet, ask, talk/teach, help, empathy, rehabilitate]. Our approach is integrated with lifesaving support IGA (income generating activities) since majority are poorest of the poor. Counseling in these institutions are linked with income generating activities where the clients rely on what advice they may get from the organization since they depend on them for their livelihood materials and accept whatever the organizers believe correct. The counseling here, therefore, seems telling what they presume sound based on the organizational objectives than counseling principles. On the contrary to Westerners society counseling, where the clients pay much to the services, the counseling giving organizations assist the clients for the survival of the individual in the holistic way through integration of both psychic and physic of the person in challenging situation. Consequently, the approaches and techniques employed by the counselors were highly dependent upon meeting the needs of the clients and availability of resources in the intended counseling.

Most counselors of the HIV counseling centers were/are overcrowded by health workers who only got three weeks training held by international organizations like Family Health International (FHI). The idea behind identifying one's emotional disturbance to give appropriate intervention was/is under question including the Orthodox Church counseling department. The notion of counseling techniques approaches to be followed and procedures to be pursued is also another issue of interest that all support providing organizations should consider. Consistent with this perspective, BPD [4] defined counseling psychology as a professional psychology field that pays attention to the "emotional, social, vocational, educational, health-related, developmental, and organizational concerns" that normally impact our daily lives. The diversity among cultural dynamic country like Ethiopia is also another area of interest that needs detailed assessment on how to conduct counseling services in such circumstances which was taken too lightly by counseling service providers. Like the result, Franklin indicated that 'although multiculturalism adds to richness in the experience derived from a country, it also presents a set of challenges that must be overcome in a variety of areas' [5].

As of the discussants in focus group conversation, it is apparent that counselors employing the modern counseling system have many accesses to different forms of trainings which are designed for counselors at each levels of counseling having their own predestined objectives even though how much these trainings are relevant to the works they are assigned on is not clear. More of the trainings provided for counselors vary from training program to the other. Some of the trainings focus on the administrative issues related to bio-data compilation, statistics of the clients who have got the service, monitoring and evaluation of health-related aids, distribution of kits registry, and number of clients getting medical support. These all have little or very limited value to add on the professional competency of the counselors in respect to the services they deliver and this in turn create meager effectiveness to the quality assurance of the service.

Focus group discussion result indicated that the understanding organizations that hire professional counselors have was/is little due to subsequent hindering factors. These are: poor advocacy the training institutions employ in advertising publicizing and putting to market on the fields they are trained. This has the worst repercussion on the demands the profession has and its marketability on the public. The other point of discern is the objectives these service giving organizations develop in organizing counseling departments under their offices. Likewise, religious based counseling departments prefer and intentionally employ advocators of that religion than working with professional personnel. The other detrimental factor is the poor philosophy different professions develop to handle certain cases as personal profession. For example, Bureau of Preparedness employed counseling offer for post-traumatic stress disorder therapy as in the case of drought or flood displacement related issues were/ are only understood as sole responsibility of health workers which totally exterminate the sense of integrative effort to treat bio-psychological disorders. The new point of deliberation is the meager consideration the government gives to social sciences, specifically field of psychology that has great application with human development, health relationship in maintaining peace and tolerance among people induced its challenge to the area. The government has minimal knowledge of human interaction or fails to notice its relevance, which puts most graduates of psychology unemployed or hardly secure jobs in their profession. Lastly, the weak effort made by psychology association to make known its profession is critical issue to be considered. Accordingly, no indication of licensing professionals and no effort were made to safeguard counseling legally and legitimately. Analogous with this result, Roisircar [6] underlined that advice by non-professionals is often moderate and based on common-sense, rather than the more specific direction for action that the counselor or therapist might give.

Any aspect of HIV counseling is rebuilding and reunification of the mental, personal, social and physical aspects of the individual which the authors believe 'the intervention component'. This area needs flexibility of the counselor to reach on agreed consensus, solution to life, adjustment and readjustment, reestablishing and stabilizing period where the individual starts thinking and planning about future life than calling for confusion or difficulty. It also has to consider wish, interest and prospect of the individual in question. So do the mental health hospitals aspiring to conduct counseling sessions for patients recovered from psychiatric challenges. What mostly observed is a push factor to professionals as to accommodate for the psychiatrist's 
order in group counseling/gathering. Another key informant stated that we are from psychology background but forced to teach English and other related or minor subjects. What we use in schools, specifically, high schools vary from place to place where some of us hold an office which is nonfunctional. In some areas, we communicate students willing to come to our office or may work on how to study and late comers. The admin, education officers, supervisors and others didn't understand the purpose of counseling. So, it seems difficult being a counselor in high school.

With regard to counseling in school settings, one of the experts explicate that there are obstructions that lead counseling service into professional service ineptness. The attention and consideration given to school guidance and counseling is unproductive; in the way that in many schools there is no counseling service or not functional if at all. On the other hand, in many schools counselors were assigned to other school activities like teaching related subjects or non-academic areas and provide counseling service as additional work. Furthermore, in some schools experienced teacher simply appointed as a counselor without professional competence. In line with this result Adane [7] elaborated that there is high need for the counselor services, but the service is not being effectively delivered and utilized in schools due to different reasons.

Counseling profession in Ethiopia is still in its infancy stage. Certainly, the counseling on course by the church seems directive since the counselor gives the clients an option that $\mathrm{s} /$ he believes better. Regarding the modern counseling system employed in Ethiopia, clients to Orthodox Church were those individuals who get there for economic support and HIV counseling provision under the church. But clients going to Emanuel Mental Health Hospital were/are those individuals facing certain forms of mental problems or individuals having psychological problems who have information about counseling provisions. The procedures these counselors employing seems by large what they assume better in assisting their clients even if they didn't follow specific procedures. Depending on the needs of the patient and/or referral of the psychiatrists in the hospital, psychotherapy may be used alone or in conjunction with other therapies and treatment methods. This type of therapy may last for just a few sessions, or treatment may last for several months, depending on the individual needs of the patient and/or the parents/care givers.

Most of the counseling services giving centers are organization driven by structural purposes than directed by counseling principles, techniques and theories applicable in the modern world [8]. Consequently, counseling procedures and techniques followed by the institutions were in line with objective of the institutions. This shows that

i. Counseling system in the country is dominated by nonprofessionals. The knowledge and attitude of the government bodies and NGOs towards counseling profession is jeopardized by nonprofessionals where no attention is/was given. ii. Counseling profession is monopolized by health workers which is evident in every HIV counseling area under most or all NGOs in the country.

iii. Counselors didn't follow proper counseling time of start and termination in the mental health hospital counseling services than waiting for the decision made by physician; specifically, health workers dominated roles on the time (counseling sessions) for the group counseling. The group counseling is composed of counselors, nurses and social workers.

iv. Most government and NGOs rely on the support rendered by counselors attending three weeks training than graduates of psychology and counseling which is evident in almost all organizations working in the area except Emanuel hospital that has realized the usefulness of counseling services in the recent years.

v. Modules and training manuals were prepared and piloted by non-professionals who are unfamiliar to psychology/ counseling and/or social work.

\section{Conclusion}

Counseling is the tradition among Oromo community even if there was no effort made through higher institutions and the government to incorporate the cultural values of counseling in the education curriculum of the country. In a nutshell, the counseling system itself is in confrontation as to what method to follow whether only relying on the spiritual matter or use the contemporary counseling system in assisting the clients in problem. On the other way, counseling institutions were striving to apply the Westerners method without considering the local community practices that exploit their services. The question of language and multicultural interaction were underemphasized due to the adherent nature of the curriculum in higher institutions. The methods employed, techniques and procedures used were poorly organized and only functional based on organizational objectives and procedures. Integrating the customary counseling system to the education curriculum and adaptation of the modern counseling methods to the level of harmonizing and pertaining to the local community custom was recommended. Besides, developing locally employed methods and principles of counseling services that could benefit the community, counseling service giving agents and the government was accentuated. Successively, to treat clients from different cultural background in the metropolitan, there is a need for successful counseling intervention accompanied by deep knowledge of cultural diversity and professional competence to reach on appropriate outcome.

\section{References}

1. Rajagopal M (2013) Counseling: A Misunderstood Profession. IOSR Journal of Humanities and Social Science (IOSR-JHSS) 11(3): 30-37.

2. Amoon P, Cooperman K (2017) Psychology, Counseling Psychology, and Professional Counseling: Shared Roots, Challenges, and Opportunities. The European Journal of Counseling Psychology 6(1): 41-62. 
3. Wendt D, Gone J, Nagata D (2015) Potentially Harmful Therapy and Multicultural Counseling: Bridging Two Disciplinary Discourses. The Counselling Psychologist 43(3): 334-358.

4. Best Psychology Degree.com (2020).

5. Franklin J (2001) The Diverse Challenges of Multiculturalism. ASCD Books and publications 43(2): 2.

6. Roysircar G (2005) Research in multicultural counseling: Client needs and counselors competence.
7. Adane W (2016) The Status of Utilization of School Guidance and Counseling Services in Ethiopian Secondary Schools in Addressing the Psychosocial and Academic Needs of Secondary School Students: The Case of Sidama Zone, SNNPRS. IOSR Journal Of Humanities And Social Science (IOSR-JHSS) 21(2): 27-35.

8. Getachew A, Tsehay B (2019) Indigenous Counseling System of Oromo Community in Ethiopia. Journal of Psychology \& Psychotherapy 9(5): $1-14$.

Your next submission with Juniper Publishers will reach you the below assets

- Quality Editorial service

- Swift Peer Review

- Reprints availability

- E-prints Service

- Manuscript Podcast for convenient understanding

- Global attainment for your research

- Manuscript accessibility in different formats

( Pdf, E-pub, Full Text, Audio)

- Unceasing customer service

Track the below URL for one-step submission

https://juniperpublishers.com/online-submission.php 